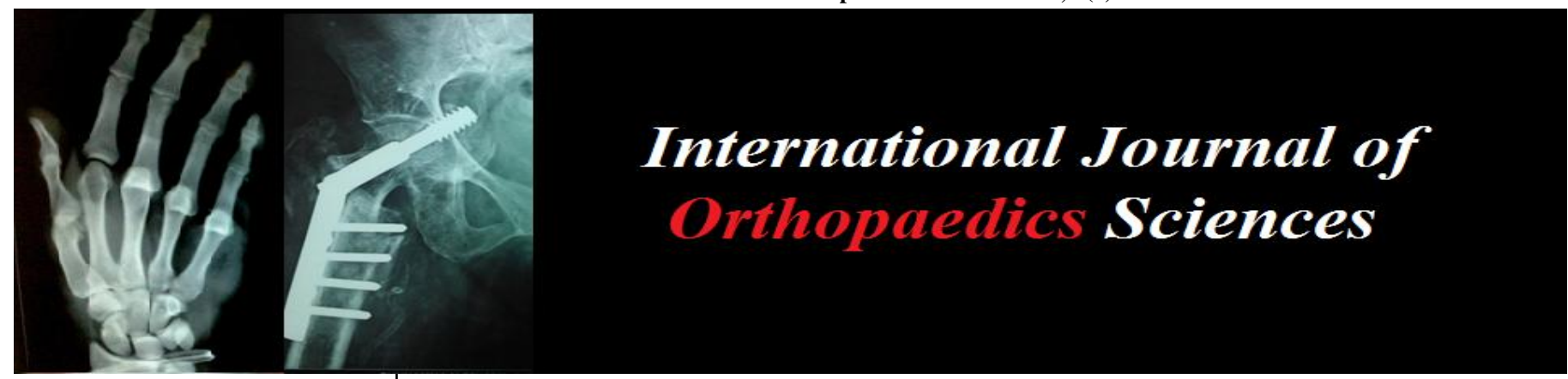

ISSN: $2395-1958$

IJOS 2017; 3(4): 324-329

(C) 2017 IJOS

www.orthopaper.com

Received: 12-08-2017

Accepted: 15-09-2017

Venkatesh Kumar N

Associate Professor, Department of Orthopaedics PSGIMSR,

Coimbatore, Tamil Nadu, India

Arvind Kumar SM

Professor, Department of

Orthopaedics PSGIMSR,

Coimbatore, India

Vetri Ganapathi

Department of Orthopaedics

PSGIMSR, Coimbatore, Tamil

Nadu, India

Sairamakrishnan S

Department of Orthopaedics

PSGIMSR, Coimbatore, Tamil

Nadu, India

Correspondence

Arvind Kumar SM

Professor, Department of

Orthopaedics PSGIMSR,

Coimbatore, India

\section{Issues in management of fractures complicated by compartment syndrome}

\author{
Venkatesh Kumar N, Arvind Kumar SM, Vetri Ganapathi and \\ Sairamakrishnan S
}

DOI: https://doi.org/10.22271/ortho.2017.v3.i4e.44

\section{Abstract}

Introduction: Compartment syndrome has been identified as an acute devastating orthopaedic emergency and early fasciotomy is the only way to prevent any complications This retrospective study proposes to analyse the issues in management of fractures complicated by compartment syndrome occurring pre-operatively and post-operatively.

Aim: To study the issues involved in the rationale for deciding the method of fracture stabilization following fasciotomy. To study the problems, complications and functional outcome of fracture stabilization. To analyze and establish methods to the optimally manage the issues involved.

Materials and Methods: A review of patients admitted in the orthopaedic department at our institution who presented with or developed compartment syndrome and associated with fractures were chosen. Passive stretch pain and serve pain out of proportion were the main clinical indicators considered. Decision to perform fasciotomy was carried out based on the differential $\mathrm{P}$ value and were treated with double incision fasciotomy Patients were followed up every month for the first 6 months and then every 6 months. All the patients, who were reviewed, were functionally assessed based on Upper Extremity Functional Index (UEFI) and Lower Extremity Functional Scale (LEFS).

Results: A high suspicion of compartment syndrome must be maintained for all cases. The early diagnosis and treatment within 12 hours is critical to reduce morbidity and prevent any long term sequale. Compartment syndrome causes delay in bone healing. Risk of infection is not increased.

Keywords: compartment syndrome, fracture healing, faciotomy

\section{Introduction}

Compartment syndrome has been identified as an acute devastating orthopaedic emergency.

Till date, compartment syndrome is one of the major complications in an injured limb. And early fasciotomy is the only way to prevent any complications due to compartment syndrome. Delay in diagnosis had been identified as the only cause of failure of treatment.

This retrospective study proposes to analyse the issues in management of fractures complicated by compartment syndrome occurring pre-operatively and post-operatively.

\section{Aim and Objectives}

Aim

To retrospectively study the issues in management of fractures complicated by compartment syndrome occurring pre-operatively and post-operatively.

\section{Objectives}

- To study the issues involved in the rationale for deciding the method of fracture stabilization following fasciotomy.

- To study the problems, complications and functional outcome of fracture stabilization.

- To analyze and establish methods to the optimally manage the issues involved.

\section{Materials and Methods}

- A review of patients admitted in the orthopaedic department at our institution was carried out. Patients who presented with or developed compartment syndrome and associated with 
fractures were chosen.

- Compartment syndrome was diagnosed clinically in all the cases, except one. Passive stretch pain and serve pain out of proportion were the main clinical indicators considered. Paraesthesia, paralysis and pulselesness were considered to be supportive of the diagnosis. Comportment pressure was measured in one patient who had a spinal injury. Decision to perform fasciotomy was carried out based on the differential $\mathrm{p}$ value. Differential $\mathrm{P}$ was calculated by the difference between the patients diastolic pressure and compartment pressure. Fasciotomy is indicated if the value was less than $30 \mathrm{~mm} \mathrm{Hg}^{24}$.

- All the patients who had developed compartment syndrome of the leg were treated with double incision fasciotomy, anterolateral and posteromedial. Compartment syndrome of forearm was treated with single volar incision fasciotomy, while that of the thigh also was treated with a single lateral incision.

- The fracture were treated with external, internal or hybrid fixation.

- The fasciotomy wounds were taken up for secondary closure from 4-7 days after fasciotomy with split skin grafting.

- Patients were followed up every month for the first 6 months and then every 6 months. All the patients, who were reviewed, were functionally assessed based on Upper Extremity Functional Index (UEFI) and Lower Extremity Functional Scale (LEFS).

- Painless unprotected weight-bearing and presence of bridging callus on X-ray were together considered as signs of bony union.

\section{Results}

There were 21 patients who were diagnosed with compartment syndrome and underwent fasciotomy for the same. But compartment syndrome in 2 of the patients were not associated with fractures and hence excluded from the study.

Incidence of compartment syndrome was found to be more common in physiologically young males, especially in the $3^{\text {rd }}$ and $4^{\text {th }}$ decades of life. This is probably due to the comparatively increased muscle mass in younger individuals.

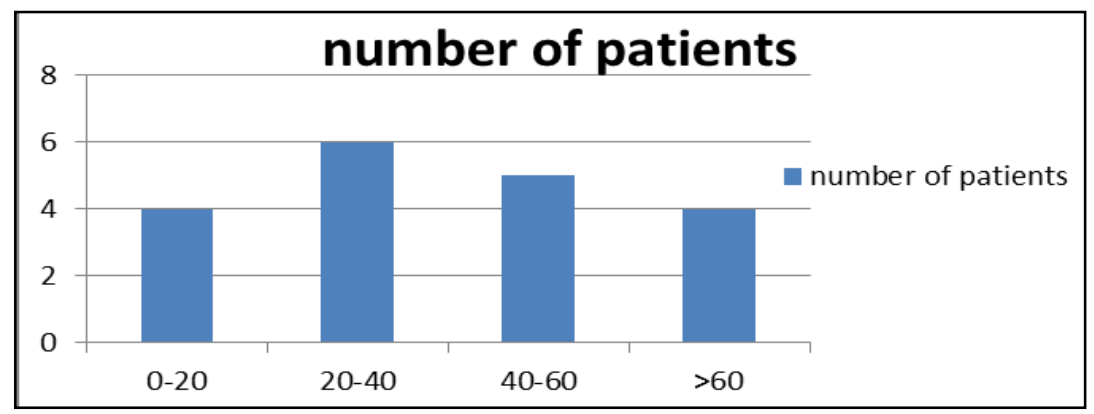

Compartment syndrome is more frequently seen in fractures due to high velocity injuries, mainly in road traffic accidents.

(Table 1)

Table 1

\begin{tabular}{|c|c|}
\hline Mode of injury & No. of cases \\
\hline Road Traffic Accident & 16 \\
\hline Fall from height & 2 \\
\hline Industrial injury & 1 \\
\hline Trivial Fall & 1 \\
\hline
\end{tabular}

Fifteen of the fractures involved Tibia. Of the fifteen Tibia fractures, three involved the Tibial plateau and one involved a proximal Tibia epiphyseal injury and the rest involved tibioal diaphysis. Compartment syndrome frequently occurs in Tibia compared to all other sites. Occurance in Proximal one third Tibial is the commonest. (Graph 3,4)
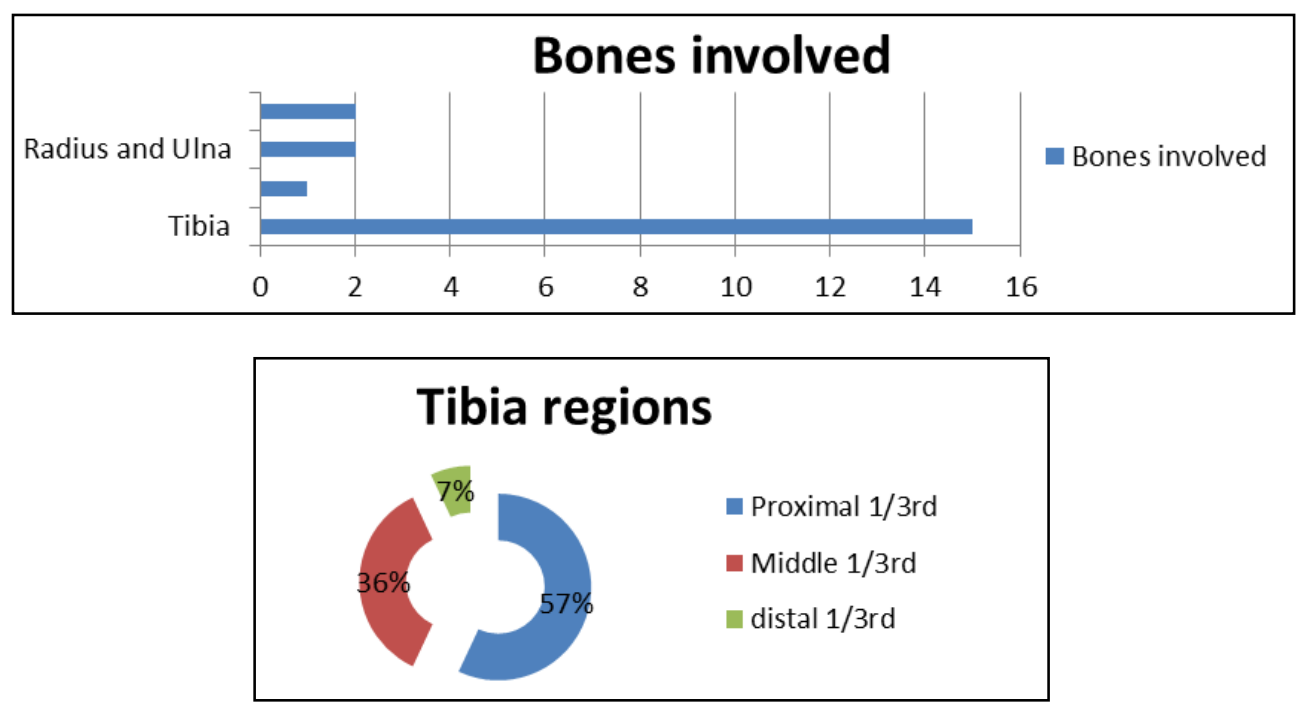
Of the remaining patients, one was a subtrochanteric fracture of the femur. The patient developed compartment syndrome of thigh probably as a consequence of the renal failure he was suffering from. Two were fractures of both bones forearm. One was a fracture around the elbow involving medial epicondyle and olecranon. One patient had additional injuries along with tibial fracture involving the ipsilateral femur and humerus and also compartment syndrome involving the forearm. One patient (Case 21) had sustained a D12 compression fracture with altered neurology of both lower limbs, along with a tibial plateau fracture (internally fixed in an institution outside). When he presented 10 days later, he had the altered neurology and also passive stretch pain with swelling of the affected leg.

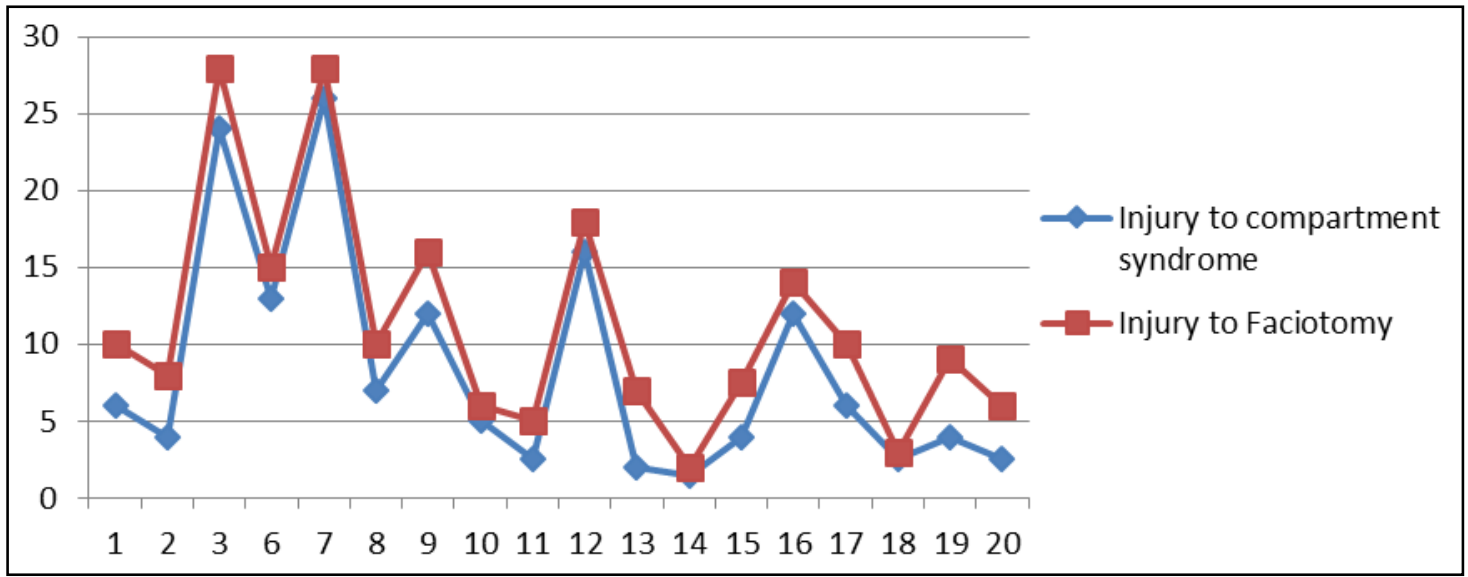

The compartment syndromes were diagnosed by clinical monitoring. The delay in development of compartment syndrome following injury was 8.3 hours (1.5 hours to 26 hours, excluding case 21 ). The average delay in performing the fasciotomy after injury was 11.3 hours $(2.5$ hours to 28 hours).

There was delay in 2 of the cases (case 3 and 7) presenting to our institution as they received first aid in an outside institution primarily. Case 21 , a 10 day old missed postoperative compartment syndrome, was not considered in the time of delay, because it was a case of established and missed compartment syndrome, on presentation from a different hospital. The patient's intra-compartmental pressure of all the compartments of the leg was measured using an electric arterial pressure monitor by an infusion technique. The differential $\mathrm{P}$ of the involved leg was found to be $10 \mathrm{~mm} \mathrm{Hg}$, indicating the need for fasciotomy. Differential $\mathrm{P}$ of the other leg was found to be $40 \mathrm{~mm} \mathrm{Hg}$.

All patients were clinically monitored for compartment syndrome from time of presentation, and also postoperatively. During the study, two distinct groups of patients were identified.

1. Patients who presented with compartment syndrome following a fracture.

2. Patients who developed compartment syndrome after surgical fixation of a fracture (cases 1, 2, 6, 8, 9 and 14)

Table 2: Grouping of patients with compartment syndrome

\begin{tabular}{|c|c|}
\hline Compartment Syndrome Following & No. of Patients \\
\hline Fracture & 12 \\
\hline Surgical fixation of fracture (s0 & 6 \\
\hline
\end{tabular}

Of the 12 patients who developed compartment syndrome after a fracture, 7 cases which were monitored from admission developed compartment syndrome. And they were taken up for fasciotomy with appropriate fixation.

Of the 18 cases considered, 6 of the fractures (cases 1, 2, 6, 8, 9 and 14), 5 tibial diaphyseal fractures and 1 ulna fracture, treated with intramedullary nailing developed compartment syndrome post-operatively. Pre-operatively, four of the fracture limbs were found to be edematous. All the 6 cases were diagnosed with compartment syndrome post-operatively after intramedullary nailing. The delay in establishing the diagnosis of compartment syndrome following intramedullary nailing was 8.5 hours (4 hours to 13.5 hours), caused probably by reduction of the fracture prior to intramedullary fixation. And the average delay in fasciotomy after intramedullary nailing was 11.8 hours (8hours to 16 hours).

Of the fifteen Tibial fractures, 6 were treated with intramedullary nailing (One-Unreamed nail), 4 were treated with Hybrid fixation, 3 were treated with external fixation and the Proximal Tibia epiphyseal injury (case 20) was treated with cancellous screw fixation. One patient with tibial plateau fracture was treated with hybrid fixator primarily. (case 17) the external fixation was converted to internal fixation primarily. (case 17) the external fixation was converted to internal fixation by means of intramedullary nailing after 3 weeks. One patient underwent internal fixation for tibial plateau fracture in an institution elsewhere before presenting to us. The subtrochanteric fracture was treated with Dynamic condylar screw and one of the forearm fractures was treated with K-wire fixation while the other was treated with Ulna square nail. And the elbow fracture was treated with internal fixation. The time lag in diagnosis, delay in fasciotomy and method of fixation of each case has been detailed in the master chart.

Except one, none of the cases had incidence infections or nonunion. The patient who developed infection was a case of missed compartment syndrome.

All the patients were reviewed with an average follow-up of 33 months (6 months to 60 months). 2 patients (case 3 and 6) died due to unrelated causes. One patient (case 21) died due to sepsis leading to multi organ failure secondary to a 10 day old missed compartment syndrome.

The average time of healing in upper limb fractures was 11 weeks ( 9 to 15 weeks) and in lower limb fractures was 17 weeks (12 to 24 weeks). In two tibial fractures, the delay in healing needed bone grafting. Healing was relatively delayed in patients who had undergone fasciotomy 10 hours after the injury or internal fixation compared to those who had gone fasciotomy in less than 10 hours, in case of both upper and lower limb fractures. 
3 patients (Case 1, 9 and 16) had neurological insult secondary to acute compartment syndrome. One patient (case 1) had weakness (Power 1/5) of the anterior compartment muscles of the leg at the time of diagnosis of compartment syndrome. He went on to recover partially (Power3/5) over a period of 3 months and then no further. Another patient had weakness (Power 3/5) of extensor hallucis longus at time of diagnosis of compartment syndrome and went on to recover in 3 weeks. One other patient (case 16) had developed severe volksmann ischemic contracture of the forearm due to delay in presentation to the hospital and hence delay in presentation to the hospital and hence delay in fasciotomy. The average in fasciotomy following injury in these cases was 13 hours (10 hours to 16 hours). Though the risk of infection is high, except one, none of our cases had any infection. Severe and extensive muscle necrosis of most of the muscles of the leg was found during fasciotomy of one of the patients (case 21), which ultimately led to sepsis and above knee amputation of the limb.

Two of the cases (case 7 and 9) had no signs of union at the end of 12 weeks both clinically and radiographically. The patients required bone grafting as a secondary procedure at 3 months to induce bony healing. The patient with volksmann ischemic contracture lost functionally of the upper limb, from elbow distally.

The functional outcome is decreased in patients who had undergone fasciotomy after 10 hours. However, younger patients showed better recovery even if they had undergone fasciotomy after 10 hours, compared to older patients.

Table 3

\begin{tabular}{|c|c|}
\hline Patient Groups & Average functional outcome \\
\hline Compartment syndrome after a fracture & $85 \%$ \\
\hline Compartment syndrome after fracture fixation & $86 \%$ \\
\hline
\end{tabular}

The average functional outcome score of the cases, excluding those lost to follow-up is 68 and percentage of maximal function is $85 \%$. The decrease in functional is $85 \%$. The decrease in functional outcome score was due to the dysfunctional status of the affected limb in case 16 . The percentage of maximal function increased to $91 \%$ on excluding case 16 . The average percentage of maximal function of cases with post-operative compartment syndrome (cases 1, 2, 8, 9) was $86 \%$, ompared to the $85 \%$ in cases primarily diagnosed with compartment syndrome $(93 \%$ on excluding case 16). Mo significant difference was found in the functional outcome of both the group of patients.

\section{Discussion}

Compartment syndrome has been extensively studied. But difficulty and delay in diagnosis of the condition is the major problem encountered. The management of fractures associated with compartment syndrome also does not have fixed guidelines.

The study analysis nearly all the issues involved in management of the compartment syndrome and the associated fractures.

The study shows that compartment syndrome commonly occurred in physiologically young males, similar to all other studies [1, 21, 25, 37]. And high velocity injuries were also identified as the major cause of compartment syndrome as in most studies ${ }^{[1,21,25,37]}$. Compartment syndrome of leg was the most common followed by that of forearm. And tibial fractures were the major cause of compartment syndrome of leg. McQueen et al showed that $36 \%$ of compartment syndromes follow tibial diaphyseal fractures. ${ }^{22}$ Of all tibial fractures, proximal tibial fractures were most commonly involved. The higher incidence of compartment syndrome in proximal tibial fractures has been attributed to the vulnerable blood supply of the popliteal artery and the posterior tibial artery, due to the vessel bifurcation and enclosing tight osse of ascial canal.

Six of our cases developed compartment syndrome after the associated fracture was treated by surgical stabilization. McQueen et al found an incidence of $5.5 \%$ compartment syndrome in fractures treated by reamed nailing compared with $12.2 \%$ in externally fixed fractures ${ }^{[22]}$ The cause of compartment syndrome in post -operative cases has been postulated to be sudden decrease in compartment size following reduction of the fracture prior to intramedullary fixation

All diagnosis of compartment syndrome were made clinically. One patient was diagnosed with compartment syndrome 10 days after internal fixation of a tibial plateau fracture. The compartment syndrome was missed due to the spinal injury sustained by the patient and altered neurology below the thoracic level. All patients with tibial and forearm fractures were monitored clinically, for stretch pain and out of proportion pain, preoperatively from admission and also postoperatively.

Cases at risk of developing compartment syndrome were identified and monitored. Measure of intra-compartmental pressure was done only for patients under nerve blocks, with altered state of consciousness, with spinal cord injury and children who are not able to express themselves. In other patients, intra - compartmental pressure was measured only when clinical signs are inconclusive and to determine the need for fasciotomy. McQueen emphasized in numerous studies that diagnosis of compartment syndrome can be made only by continuous monitoring of the intra -compartmental pressure $[4,21,22,23,24]$. Continuous intra-compartmental monitoring is preferred to a single reading. However, Twaddle and Amendola stressed that continuous monitoring of all patients due to the need for equipment and manpower. They advised clinical monitoring to diagnose compartment syndrome and to measure intra compartmental pressure in a specified group of patients as mentioned above. And they observe that the judicious use of monitoring is required to prevent over diagnosing compartment syndrome.

Turen proposed that skeletal stabilization of fractures was needed immediately after fasciotomy to aid in the healing of soft tissues which was also concurred by Twassle and Amandola ${ }^{[36,37]}$. Georgidas and Hake et al observed that closed fractures and uncontaminated open fractures, presenting with compartment syndrome, can be treated with primary internal fixation following fasciotomy, as there are low or negligible risks of infection and non-union. ${ }^{[9,11]}$ And this treatment protocol simplifies the bony and soft tissues cover must be obtained to cover the implant and fracture site. Twaddle and Amendola observed that the stabilization technique used depends on the location and character of the fracture and the skill of the surgeon, but should minimize operative trauma to a limb that may already have had its 
circulation compromised. Therefore, if possible, intramedullary nailing to stabilize the bone (and hence the soft tissues) is recommended. After the osteosynthesis has been completed, soft tissues coverage over the bone should be attempted ${ }^{[37]}$.

All the fractures in our study were stabilized after fasciotomy by external fixation or internal fixation. Following fasciotomy, the fracture was considered to be an open one.

In metaphyseal and metaphyseal-diaphyseal fractures, we used external fixation as the method of choice for primary stabilization, We used external fixation for primary method of stabilization in 9 of the 15 tibial fractures. For juxta-articular fractures, we used external fixators or hybrid fixators. Hybrid fixators with inter fragmentary screw fixation were used in 4 cases of which 2 were tibial plateau fractures. The integrity of the articular surface was maintained by means of the hybrid fixators. The advantages of external fixation are the safety and ease of application, less devitalization of soft tissues and decreased operating time. Difficulties were faced early mobilization of the patient and wound care.

Of the 6 tibial diaphyseal fractures, 5 were treated primarily by means of external fixation. External fixation was used in diaphyseal fractures, when there was delay in fasciotomy and the viability of the muscles were in doubt and in cases without adequate soft tissues cover following fasciotomy. One of the cases treated with external fixator was taken up for intramedullary nailing at the earliest. The intramedullary conversion increased patient compliance. One tibial diaphyseal fracture was primarily treated with unreamed intramedullary nailing. Wound management was found to be easier after the internal fixation and the patient was also mobilizes early. Early mobilization, easy accessibility to the fasciotomy wounds for wound care, considerable decrease in the bulk of the implant and patient compliance are the advantage of intramedullary internal fixation.

Plate osteosynthesis was never considered in any of the tibial fractures, as the risk of devitalizing the already compromised soft tissues and infection were high.

Bony healing was delayed in all cases irrespective of method of stabilization. Time of bony healing did not differ much from that of post-operative compartment syndromes. In both the groups of patients, those who presented with compartment syndrome following an injury and those who developed compartment syndrome after internal fixation, the fracture was considered to be open. Both the groups had delayed bone healing. The average time of bone healing was nearly the same in bothgroups. And the functional outcome of both the groups of patients was nearly the same. Acute complications encountered in our study were neurological insult in three of the patients who underwent delayed fasciotomy of the three, one patient recovered completely, another patient had incomplete recovery, while the third patient had no neurological recovery. Incomplete recovery or total absence of recovery is due to the development of myonecrosis during the compartment syndrome and consecutive fibrosis of the muscles [27, 29].

Delay in diagnosis is primarily due to the delay in presentation to our centre.

Infection of the fasciotomy wounds and fracture site are expected. Fracture site is exposed during fasciotomy and the fasciotomy wound is left open for secondary closure increasing thechaces of infection. In our study, none of the cases developed infection at the fracture site of fasciotomy wound.

All the cases in our study, including the cases that developed compartment syndrome post-operatively, had delayed bone healing. This is probably due to loss of fracture haematoma during fasciotomies. But bone healing was further delayed I patients who underwent fasciotomy after 10 hours compared to those who underwent fasciotomy earlier. Similar results were also observed by Mullet ${ }^{[27]}$. Court-Brown and McQueen found that complication rates decreased to $4 \%$ from $54 \%$ with early fasciotomy ${ }^{[4]}$.

Functional outcome was decreased I our patients who had undergone fasciotomy after 1 hours. Younger patients showed better functionality. The functional outcome of patients who had post-operative compartment syndrome was no different from those who had presented with compartment syndrome. The functional outcome of any case is determined mainly by the delay in fasciotomy followed by age than any other factor. Mullet et al found that younger patients had better functional outcome. This was attributed due to change in the muscle fiber composition and decreased muscle regeneration due to age ${ }^{[27]}$.

Shortcomings of the study are the limited of number patients, the absence of a control group and also the analysis being done retrospectively. The chance of developing compartment syndrome has decreased considerably due to the early intervention following injury and advancement in monitoring patients early. In spite of these limitations $\mathrm{zX}$, the factors influencing the outcome of the fractures associated with compartment syndrome were identified.

Orthopaedic surgeons must remain vigilant to identify compartment syndromes, both in in- patient and out- patient settings. Future development is likely to center around noninvasive methods of diagnosing acute compartment syndrome is being examined, like near infrared spectroscopy, which measures the amount of oxygenated hemoglobin in muscle tissues transcutaneously.

\section{Conclusion}

- A high suspicion of compartment syndrome must be maintained for all cases.

- The early diagnosis and treatment within 12 hours is critical to reduce morbidity and prevent any long term sequale.

- Compartment syndrome causes delay in bone healing.

- Risk of infection is not increased.

- External fixation is the method of choice in metaphyseal and metaphyseal-diaphyseal fractures and fractures without adequate soft tissue cover, when associated with compartment syndrome.

- Hybrid fixators with intra fragmentary screw fixation are used in juxta-articular fractures with communition.

- As bony healing is not compromised in any way, use of intramedulluary fixation is not contraindicated in diaphyseal fractures associated with compartment syndrome.

\section{References}

1. Azar FM. Compartment syndromes. In: Canale ST, Beaty JH, eds. Campbell's Operative Orthopaedics. 11th ed. Philadelphia, Pa: Mosby Elsevier, 2007, 46.

2. Berman SS, Schilling JD, McIntyre KE, et al. Shoelace technique for delayed primary closure of fasciotomies. Am J Surg. 1994; 169:435-436.

3. Blick SS, Brumback RJ, Poka A, et al. Compartment syndrome in open tibial fractures. J Bone Joint Surg Am. 1986; 68:1348.

4. Court-Brown CM, McQueen MM. Compartment 
syndrome delays tibial union. Acta Orthop Scand. 1987; 58:249-252.

5. DeLee JC, Stiehl JB. Open tibia fracture with compartment syndrome. Clin Orthop. 1987; 160:175-84.

6. Fitzgerald AM, Gaston P, Wilson Y, et al. Long term sequelae of fasciotomy wounds. Br J Plast Surg. 2000; 53:690-693.

7. Galanakos S, Sakellariou VI, Kotoulas H, Sofianos IP. Acta Orthopaedica et Traumatologica Hellenica. 2009; 60(2):127-133.

8. Garfin S, Mubarak SJ, et al. Quantification of intercompartmental pressure and volume under plaster casts. J Bone Joint Surg. 1981; 63-A:449-53.

9. Georgiadis GM. Tibial shaft fractures complicated by compartment syndrome: treatment with immediate fasciotomy and locked unreamed nailing. J Trauma. 1995; 38(3):448-452.

10. Gershuni DH, Mubarak SJ, Yaru NC, Lee YF. Fracture of the tibia complicated by acute compartment syndrome. Clin Orthop. 1987; 217:221.

11. Hak. The use of the unreamed nail in tibial fractures with concomitant preoperative or intraoperative elevated compartment pressure or compartment syndrome. J Orthop Trauma. 1994; 8(3):203-11.

12. Heckman MM, Whitesides Jr TE, Grewe SR, et al. Histologic determination of the ischemic threshold in the canine compartment syndrome model. J Orthop Trauma. 1993; 7:199.

13. Heckman MM, Whitesides TE Jr, Grewe SR, et al. Compartment pressure in association with closed tibial fractures: Therelationship between tissue pressure, compartment, and the distance from the site of the fracture. J Bone Joint Surg Am. 1994; 76:1285-1292.

14. Janzing $\mathrm{H}$, Broos $\mathrm{P}$. Dermotraction: an effective technique for the closure of fasciotomy: A preliminary report of fifteen patients. J Orthop Trauma. 2001; 15:438441.

15. Katz LM, Nauriyal V, Nagaraj S, Finch A, Pearlstein K, Szymanowski A. Infrared imaging of trauma patients for detection of acute compartment syndrome of the leg. Crit Care Med. 2008; 36(6): 17.

16. Koval KJ, Clapper MF, Brumback RJ, et al. Complications of reamed intramedullary nailing of the tibia. J Orthop Trauma. 1991; 5:184-189.

17. Lindsay TF, Liauw S, Rouraschin AD, et al. The effect of ischaemia/reperfusion on adenosine nucleotide metabolism and xanthine oxidase production in skeletal muscle. J VascSurg. 1990; 12:8-15.

18. Matava MJ, Whitesides TE Jr, Seiler JG Ill, et al. Determination of the compartment pressure threshold of muscle ischemia in a canine model. J Trauma. 1994; 37:50-58.

19. Matsen III FA, Mayo KA, Sheridan GW, Krugmire Jr RB. Monitoring of intramuscular pressure. Surgery. 1976; 79:702.

20. Matsen FA III, Mayo KA, Krugmire RB, et al. A Model Compartmental Syndrome in Man with Particular Reference to the Quantification of Nerve Function. J Bone Joint Surg. 1977; 59-A:648.

21. McQueen MM. Acute Compartment syndrome. In: Bucholz RW, Heckman JD, Court-Brown CM, eds. Rockwood \& Green's Fractures in Adults. 6th ed. Philadelphia, Pa: Lippincott Williams \& Wilkins. 2006, 13.

22. McQueen MM, Christie J, Court-Brown CM.
Compartment pressures after intramedullary nailing of the tibia. J Bone Joint surg Br. 1990; 72:95-98.

23. McQueen MM. The Effect of Acute Cornpartment Syndrome on Bone Blood Flow and Bone Union. MD Thesis, University of Edinburgh, 1995.

24. McQueen MM, Court-Brown CM. Compartment monitoring in tibial fractures. J Bone Joint Surg Br. 1996; 78:99.

25. Meyer RS, Mubarak SJ. Compartment syndromes. In: Chapman MW, eds. Chapman's Orthopaedic Surgery. 3rd ed. Philadelphia, Pa: Lippincott Williams \& Wilkins, 2001, 13.

26. Moed BR, Strom DE. Compartment syndrome after closed intramedullary nailing of the tibia: a canine model and report of two cases. J Orthop Trauma. 1991; 5:71-77.

27. Mullett H, Al-Abed K, Prasad CV, et al. Outcome of compartment syndrome following intramedullary nailing of tibialdiaphyseal fractures. Injury. 2001; 32(5):411-3.

28. Nario CV. La enfermedad de Volkman experimental. Ann Fac Med Montivideo. 1938; 10:87-128.

29. Nassif JM, Gorczyca JT, Cole JK, et al. Effect of acute reamed versus unreamed intramedullary nailing on compartment pressure when treating closed tibial shaft fractures: a randomised prospective study. J Orthop Trauma. 2000; 14:554-558.

30. Petrasek PF, Homer-Vanmasinkam S, Walker PM. Determinants of ischaemic injury to skeletal muscle. J Vasc Surg. 1994; 19:623-631.

31. Rang M. Injury. In: Rang $M$, eds. The story of Orthopaedics. 1 sted. Philadelphia, Pa: W.B. Saunders. 2001, 16.

32. Rorabeck $\mathrm{CH}$. The treatment of compartment syndromes of the leg. J Bone Joint Surg Br. 1984; 66:93.

33. Rorabeck $\mathrm{CH}$, Macnab L. Anterior tibial compartment syndrome complicating fractures of the shaft of the tibia. J Bone Joint Surg Am. 1976; 58:549.

34. Shakespeare DT, Henderson NJ. Compartmental pressure changes during calcaneal traction in tibial fractures. J Bone Joint Surg Br. 1982; 64:498-499.

35. Tornetta P, French BG. Compartment pressures during nonreamedtibial nailing without traction. J Orthop Trauma. 1997; 11:24-27.

36. Turen $\mathrm{CH}$. Skeletal stabilization for tibial fractures associated with acute compartment syndrome. Clin Orthop Relat Res. 1995; 315:163-168.

37. Twaddle BC, Amendola A. Compartment syndrome. In: Browner BD, Jupiter JB, Levine AM, Trafton PG, Krettek C, eds. Skeletal Trauma. 4th ed. Philadelphia, Pa: Saunders Elsevier, 2008, 13.

38. Webb LX. New techniques in wound management: vacuum assisted wound closure. J Am Acad Orthop Surg. 2002; 10:303-311.

39. Whitesides Jr. TE, Haney TC, Morimoto K, Hirada H. Tissue pressure measurements as a determinant for the need of fasciotomy. Clin Orthop. 1975; 113:43.

40. Whitesides Jr TE, Heckman MM. Acute Compartment Syndrome: Update on Diagnosis and Treatment. J Am Acad Orthop Surg. 1996; 4:209-218.

41. Vrahas M, Bhattacharyya T. The Medical-Legal Aspects of compartment Syndrome. J Bone Joint Surg Br. 2004; 86A:864-868 